\title{
A ACCOUNTABILITY SOCIAL JUDICIAL NO CONTEXTO DA JURISTOCRACIA BRASILEIRA
}

\author{
Lucas Gabriel Troyan Rodrigues ${ }^{1}$
}

Claudia Maria Barbosa ${ }^{2}$

\begin{abstract}
Resumo
O protagonismo do Poder Judiciário para resolução de controvérsias que ultrapassam a esfera jurídica atrelado à ausência de mecanismos eficientes de controle e responsabilização fragilizam a sua legitimidade, bem como o próprio modelo democrático, acarretando a Juristocracia, assim, para resgatar a legitimidade do Judiciário analisa-se a correspondência entre a necessidade de participação social na Política Judiciária e processo decisório e a indispensável função contramajoritária que compete a este Poder. Partiu-se de pesquisa bibliográfica na doutrina nacional e estrangeira para delimitação dos temas, empregando a metodologia dedutiva e análise qualitativa do material. A ascensão do Poder Judiciário no cenário da Juristocracia tem como principal causa a preservação hegemônica, pela qual as elites sociais, econômicas e políticas transferem de forma deliberada o poder decisório ao Judiciário com o propósito de resguardar seus interesses frente à ameaça advinda da eleição de representantes políticos mais alinhados ao povo, e portanto, distantes dos interesses dos grupos dominantes, o que encontra forte correspondência com o cenário político brasileiro. Assim, denota-se a iminente necessidade de estabelecer mecanismos de controle e responsabilização ao Judiciário e seus membros, especialmente no que concerne à participação social, encontrando respaldo na accountability social, a qual não visa formar um tribunal de maiorias, mas apenas torna-lo mais dialógico e democrático para promover a efetiva integração do Judiciário com a sociedade, fortalecendo e resguardando as garantias fundamentais atreladas a função contramajoritária, haja vista que quanto mais plural for a sociedade, na mesma proporção deverão ser os critérios de participação. Deste modo, nota-se o fenômeno político da Juristocracia no cenário brasileiro em decorrência das atuações do Poder Judiciário inferindo na atividade política, e por vezes, substituindo suas decisões, sem qualquer mecanismo eficiente de controle ou participação social capaz de legitimar tal atuação, contribui para demolição dos alicerces democráticos e desestabiliza a separação de poderes.
\end{abstract}

Palavras-Chave: Política Judiciária; Participação Cidadã; Juristocracia; Função Contramajoritária; Accountability.

\section{INTRODUÇÃO}

A ascensão de protagonismo do Poder Judiciário em relação aos demais poderes da República tornou-se notória no cenário brasileiro a partir das inúmeras formas de judicialização da política e transferência de controversas polêmicas ao Judiciário para evitar custos políticos e resultar em uma decisão aparentemente técnica fruto de aspectos jurídicos.

\footnotetext{
${ }^{1}$ Mestrando em Direito na Pontifícia Universidade Católica do Paraná e bacharelando em Direito na mesma instituição por meio do PIBIC Master (dual degree), E-mail: lucas.troyan@ hotmail.com.

${ }^{2}$ Professora Titular do Programa de Pós-Graduação da Pontifícia Universidade Católica do Paraná (Mestrado e Doutorado). Doutora e Mestre em Direito pela Universidade Federal de Santa Catarina, E-mail: claudia.mr.barbosa@gmail.com.
} 
Assim, tem-se a necessidade de analisar a correspondência do cenário brasileiro atual com o fenômeno denominado juristocracia, no qual há transferência deliberada dos processos decisórios ao Judiciário por parte das elites para preservar seus interesses e privilégios frente à ascensão de atores políticos mais alinhados aos interesses sociais, e, portanto, incompatíveis com os interesses elitistas.

Este fenômeno afeta diretamente a legitimidade do Poder Judiciário perante a sociedade vez que passa a exercer uma função que não lhe é atribuída pelo texto constitucional, bem como pela ausência de mecanismos que possibilitem o controle por parte dos cidadãos em relação as suas decisões políticas, pois não se submete ao controle eleitoral como os agentes políticos.

Com isso, a partir de pesquisa bibliográfica na doutrina nacional e estrangeira para delimitação dos temas, empregando a metodologia dedutiva e análise qualitativa do material, buscar-se-á analisar se os mecanismos de accountability social, pautados na participação, controle e responsabilização, poderão enfraquecer o cenário de juristocracia por meio de formas de integrem ou ao menos aproximem o Poder Judiciário da sociedade a fim de atribuir-lhe maior legitimidade, e ainda, se estes mecanismos por decorrerem diretamente da cidadania ativa poderão afetar negativamente a função contramajoritária inerente à concepção do Poder Judiciário em um Estado de Democrático de Direito fundado no texto constitucional.

Deste modo, inicialmente retrata-se o fenômeno da juristocracia com seus principais aspectos teóricos assimilando-a ao cenário brasileiro, para em seguida abordar a necessidade de mecanismos de accountability social para enfraquecer este fenômeno, bem como fortalecer a legitimidade do Judiciário perante a sociedade analisando sua compatibilidade com a função contramajoritária deste Poder.

\section{JURISTOCRACIA NO CENÁRIO BRASILEIRO}

$\mathrm{Na}$ pioneira teoria de separação de poderes que norteia os países democráticos constitucionais, o Poder Judiciário ocupava função neutra, não oferecendo riscos a solidez constitucional. Entretanto, especialmente no último século, tornou-se protagonista em momentos de grande importância social, agindo de forma política e deliberando sobre assuntos que competem ao Parlamento, desestabilizando o equilíbrio entre os Poderes da República e a própria estabilidade democrática, tornando-se ainda mais prejudicial a ausência de mecanismos de controle sobre a atuação deste poder. 
Nesta pesquisa selecionam-se duas principais correntes que buscam explicar o agigantamento do Poder Judiciário. A primeira, sustentada, entre outros, pelo magistrado francês, Antonie Garapon (1999), para quem o protagonismo político do Judiciário é consequência da incompetência do sistema representativo em adimplir com as expectativas de justiça e igualdade esculpidas nas constituições contemporâneas, restando à sociedade recorrer ao Judiciário como guardião do texto constitucional e em última análise dos próprios ideais democráticos.

Neste trabalho afasta-se essa perspectiva, haja vista que o descrédito de legitimidade dos demais poderes não pode ser subterfúgio para o empoderamento judicial e a ausência de ação por parte dos agentes eletivos pode ser uma decisão política na esfera de atuação como representantes dos anseios sociais.

O empoderamento do Judiciário não fortalece o texto constitucional, mas pelo contrário, contribui para demolição dos alicerces democráticos desestabilizando a separação de poderes, além de muitas vezes suprimir as liberdades individuais com respaldo em uma relativa sensação de alívio e necessidade momentânea. (ABBOUD, 2016, p. 2) Especificamente no caso brasileiro, nota-se que sob o fundamento de combate à corrupção o Judiciário tem restringido inúmeras garantias fundamentais.

A segunda corrente está bem ilustrada no posicionamento de Ran Hirschl (2016) estabelecendo um modelo de Estado denominado Juristocracia, que consiste em um fenômeno político no qual há preponderância do Poder Judiciário sobre os demais Poderes, cabendo ao Judiciário manifestar-se sobre questões controversas na sociedade, muitas vezes de viés puramente político. A concentração dos debates no Judiciário acaba por suprimir outros debates democráticos e o dissenso acaba por ficar escondido sob o manto de uma decisão aparentemente técnica.

O protagonismo alcançado pelo Judiciário não se dá pela inércia das esferas representativas ou pela constitucionalização do direito, embora esses possam ser fatores que o favorecem, mas por aquilo que Hirschl denomina preservação hegemônica.

A preservação hegemônica se dá quando as elites sociais, políticas e econômicas transferem o poder decisório ao Judiciário de forma deliberada, ao se considerarem ameaçadas pela ascensão de agentes políticos representantes do interesse social, e portanto incompatível com os preferências das elites, com intuito de assegurar seus interesses pela via jurídica que de algum modo também são compatíveis com os interesses da magistratura por situarem-se na mesma condição socioeconômica.

Para os agentes políticos, consiste em um eficiente mecanismo de transferir a responsabilidade política perante seu eleitorado, de modo que redireciona questões controversas que 
são potencialmente impopulares aos magistrados que não são responsabilizáveis politicamente e possuem maior credibilidade frente a sociedade para tais decisões. (HIRSCHL, 2016, p. 752)

Assim, o Judiciário figura como um amortecedor político, considerando que diante de controversas custosas ao capital político dos representantes eleitos, transfere-se a tomada de decisão para interpretação aparentemente técnica do texto constitucional, neutralizando os debates políticos, bem como corroborando para manutenção do poder das classes elitistas. (BARBOSA, 2019, p. 16)

Portanto, a juristocracia consiste na transferência de poder pelas elites políticas, econômicas, sociais e jurídicas para o Poder Judiciário, a fim de garantir seus interesses. Enquanto nas urnas era possível eleger governos que representassem os interesses dessas elites, o poder com elas permanece. Contudo, no momento em que regras democráticas eleitorais acabam por permitir que governantes mais afinados com os interesses populares sejam eleitos, as elites se veem ameaçadas. Como o Judiciário é parte das elites, e compartilha com esses grupos valores semelhantes, a transferência de poder político ao Judiciário acaba sendo deliberada, com o consequente empoderamento do Judiciário. A juristocracia, portanto, refuta a hipótese de que o protagonismo político do Judiciário seja consequência "natural” da constitucionalização de direitos.

De acordo com Ran Hirschl, a judicialização da política subdivide-se em três faces que estão relacionadas, a primeira consiste na judicialização das relações sociais quais são dominadas por regras e procedimentos jurídicos resultando em decisões judiciais para dirimir quaisquer controvérsias, refletindo na esfera política. (HIRSCHL, 2016, p. 723)

A segunda face baseia-se na judicialização de políticas públicas via controle de constitucionalidade, e a ratificação dos limites entre os órgãos estatais, com objetivo de tornar as decisões jurídicas como soluções aos problemas políticos, sem que o Judiciário esteja sujeito às restrições que os demais poderes estão, principalmente no que concerne as verbas orçamentarias relacionadas as políticas públicas. Deste modo expande o poder dos magistrados sob os atos da administração pública, possibilitando até mesmo a interferência nas políticas públicas, podendo caracterizar-se em uma transição para juristocracia. (HIRSCHL, 2016, p. 726)

A terceira face possui maior relevância política, constitui-se pela judicialização da política pura ou também denominada de megapolítica, ou seja, assuntos cuja natureza e significado são nitidamente políticos, que devem ser apreciados pela própria sociedade, por meio de seus representantes responsabilizáveis na esfera eleitoral, haja vista que o enfrentamento de tais questões é inerente ao exercício político, não havendo legitimidade aos tribunais para deliberar acerca de controversas políticas centrais que estabelecem uma sociedade. (HIRSCHL, 2016, p. 728) 
Deste modo, o Poder Judiciário brasileiro adentra em questões políticas inicialmente para efetivar os inúmeros direitos previstos no texto constitucional, reconhecendo sua força normativa e caráter de transformação social, acarretando a esperança de parcela da sociedade não atendida pelos entes políticos, justificando-se à luz da Constituição Federal por efetivar os fundamentos e objetivos da República, dentre estes o combate às desigualdades. (BARBOSA, 2019, p. 18)

Todavia, a crise política e econômica que assola o país em decorrência da ascensão de governantes distantes dos interesses elitistas, principalmente após a reeleição da Presidente Dilma Rousseff, gerou o protagonismo do Poder Judiciário nos processos políticos atrelado à uma atuação punitivista contraria as diretrizes constitucionais pelo desmonte de direitos e garantias fundamentais. Acarretando "o paradoxo de ser a um só tempo poderoso, pela força de suas decisões e fragilidade do controle que se possa exercer sobre ele; e fraco, porque deslegitimado perante a sociedade." (BARBOSA, 2019, p.19)

A hipótese de preservação hegemônica para caracterização da juristocracia tornar-se mais evidente diante da chancela do Poder Judiciário à um processo de impeachment infundado sustentado por mobilizações das elites, bem como pela atuação seletiva e estratégica de parcelas do Judiciário para influir nos resultados eleitorais para garantir a ascensão de governantes mais alinhados aos interesses elitistas.

Além da paradigmática decisão citada por Vieira (2008), em que o Judiciário a partir de uma deliberação acabou por criar uma nova hipótese para perder o mandato parlamentar eletivo por infidelidade partidária, alterando a jurisprudência da Corte e inovando, sem observar o princípio da legalidade, no contexto político brasileiro em uma prática corriqueira para formar e fortalecer as bases de governo, consolidando a influencia judicial na esfera política em detrimento do governo da época.

Por outro lado, reconhecendo o imenso acervo processual no sistema de justiça brasileiro e buscando maior celeridade, o advento do Código de Processo Civil (Lei nº 13.105/2015) corrobora com este cenário, pela atribuição imoderada de efeitos vinculantes as decisões exaradas nas Cortes Superiores e mecanismos de resolução de demandas repetitivas, buscando importar de forma errônea a teoria de precedentes típica dos sistemas common law, haja vista que o legislador não observou pressupostos e etapas básicas da utilização de precedentes para solucionar um caso concreto, buscando atribuir as referidas Cortes somente a função de criação e fixação de teses jurídicas ignorando as funções típicas atribuídas à estes na Constituição Federal, principalmente no que concerne a proteção de direitos fundamentais e a expressa competência recursal, além de não 
prever mecanismos que possibilitem a revisão da jurisprudência firmada. (NERY e ABBOUD, 2016, p. 228)

Nesta toada, tem-se a abordagem de Vieira (2008) na qual cunha a expressão supremocracia referindo-se à ascensão de protagonismo do Supremo Tribunal Federal, deliberando sobre questões que fogem de sua esfera tradicional decisória, inovando no ordenamento jurídico sem a devida legitimidade para tanto.

As circunstâncias tornam-se ainda mais temerárias quando se analisa a atuação monocrática dos ministros do Supremo Tribunal Federal, por meio de liminares sobre temáticas de extrema relevância que na maioria dos casos não são submetidas ao Plenário, e ainda que fossem, estavam impossibilitadas de retornar ao status quo ante. De igual maneira, o controle exercido pelos ministros sob a agenda do tribunal, considerando que em inúmeros casos, mais importante que a própria decisão é o momento em que a mesma será realizada, de modo que a atuação individual dos ministros possibilita estratégias de atores políticos, dando ensejo ao cenário de ministocracia. (ARGUELHES e RIBEIRO, 2018)

\section{ACCOUNTABILITY SOCIAL E A FUNÇÃO CONTRAMAJORITÁRIA DO PODER JUDICIÁRIO}

Para adentrar neste tópico, tem-se a necessidade de demonstrar o fundamento para adoção de mecanismos de accountability social, ou seja, como estes mecanismos poderão aprimorar a organização do Poder Judiciário, ao ponto de integrá-lo à sociedade, enfraquecendo o fenômeno da Juristocracia e fortalecendo sua legitimidade decisória.

Assim, remete-se à pioneira obra de Cappelletti, Juízes Irresponsáveis, na qual retrata a crescente margem decisória pelo processo interpretativo do direito, acarretando no protagonismo do Poder Judiciário, dando ensejo a tendência global em submeter os juízes à alguma forma de controle para maximizar sua eficiência e conduta, todavia, sem mitigar por completo sua autonomia e independência, vez que essenciais para o exercício jurisdicional e a garantia da imparcialidade. (CAPPELLETTI, 1989, p. 24-32)

Diante disso, o autor estabelece três modelos de responsabilidade, (I) repressivo, no qual há sujeição do Judiciário às forças políticas dominantes, (II) autônomo-corporativo, marcado pela autorregulamentação da magistratura em uma independência absoluta, ao ponto de se isolar da sociedade, e (III) responsabilização social, concebido em função dos consumidores da justiça, os 
cidadãos, com legítimo grau de abertura e sensibilidade para sociedade. Modelo que busca compatibilizar as formas de responsabilidade e a indispensável independência, refletindo a base da República, de que todo poder deve estar submetido à um controle. (CAPPELLETTI, 1989, p. 80-91)

Com isso, verifica-se no cenário brasileiro, o que é preponderante para o fenômeno da juristocracia, que o Poder Judiciário se enquadra no modelo autônomo-corporativo da tipologia elaborada por Cappelletti, considerando a independência institucional e individual de seus respetivos membros, bem como os mecanismos de controle e responsabilização ocorrem por meio de seus pares em órgãos internos e administrativos do Judiciário, dentre estes o Conselho Nacional de Justiça.

Nas palavras de O’Donnell ao analisar este aspecto, constata:

"O Brasil é um exemplo disso. Nesse país, o Judiciário obteve um alto grau de autonomia em relação ao Executivo e ao Congresso, sem que isso significasse uma melhoria de seu desempenho (no mais, extremamente fraco). Mas o Judiciário tem usado sua autonomia para atribuir aos juízes e aos outros funcionários salários especialmente altos e, principalmente no caso dos Tribunais Superiores e em outros Tribunais, privilégios imensos. (O’Donnell, 1997, p. 49, sem grifos no original)

O modelo burocrático profissional próprio da carreira da magistratura brasileira, por seus próprios fundamentos, induz uma atuação essencialmente antidemocrática, fundamentada nos próprios elementos que constituem o Estado Democrático dando ensejo a sua legitimação jurisdicional, em especial na esfera da jurisdição constitucional, onde mais exerce sua função contramajoritária.

A função contramajoritária, por sua vez, também é expressão do caráter antidemocrático do Judiciário, uma vez que pressupõe a defesa de direitos de minorias contra a vontade implícita, ou por vezes, expressa da maioria.

Ante esse alegado déficit democrático do Judiciário, a sua base de sustentação, ou seja, o seu fundamento de legitimidade é a defesa intransigente da Constituição, expressão do poder constituinte originário que, na perspectiva do estado democrático de direito, expressa a vontade da sociedade.

A judicialização da vida, contudo, acabou por transferir poder sobre questões corriqueiras ao Judiciário e, no outro extremo, também problemas da macropolítica foram transferidos ao Poder Judiciário, de forma a ultrapassar a sua função ordinária, podendo inclusive afetar a sua legitimidade perante a sociedade, além de que tais decisões oriundas de um seleto grupo de pessoas não eleitas para tal finalidade poderá caracterizar um cenário de juristocracia. (REZENDE, 2018, p. 
Neste ínterim, insere-se a demanda por accountability social no Brasil, para possibilitar a transição do modelo autônomo-corporativo para o modelo que considera os cidadãos como consumidores do sistema de justiça, afastando o Poder Judiciário de sua atual postura elitista para que tenha maior legitimidade perante a sociedade, bem como integrando-o a sociedade que o compõem, a partir do equilíbrio entre independência, responsabilidade e controle social, evitando o isolamento da magistratura. (CAPPELLETTI, 1989, p. 10).

Em especial, ao analisar que a legitimidade do Poder Judiciário se dá de forma prévia pela formação do Estado no próprio texto constitucional, sendo esta uma legitimação formal, entretanto não poderá estar dissociada da legitimação posterior que se dá por atingir determinados objetivos, de modo que poderá proporcionar ao Judiciário a legitimidade além do formalismo, alcançando a legitimidade material. (REZENDE, 2018, p. 90-92)

Assim, a jurisdição democrática não se esgota com a legitimidade formal que garante a autoridade do Poder Judiciário, mas depende essencialmente de sua atuação pautada no texto constitucional, proteção aos direitos fundamentais e minorias, buscando efetivar os objetivos da República, o próprio Estado Democrático de Direito, para garantir sua legitimidade material. (REZENDE, 2018, p. 94)

Neste sentido, os mecanismos de accountability demonstram-se essenciais para manutenção e fortalecimento do regime democrático, ao ponto que o Judiciário não tenha sua legitimidade questionada ao exercer a função contramajoritária, visto que não se tornará um tribunal de maiorias, mas com sensíveis aberturas à sociedade, pois as diretrizes constitucionais deverão ser observadas por todos os poderes da República para proteger as garantias consagradas no texto constitucional de maiorias momentâneas, vinculando até mesmo o Poder Legislativo, majoritário por excelência. (ABBOUD, 2018, p. 832-834)

De igual maneira, Georges Abboud (2018, p. 366-371), ao comentar a decisão do Supremo Tribunal Federal acerca da constitucionalidade da Lei da Ficha Limpa, particularmente o voto do Min. Luiz Fux que fundamentou-o na "fortíssima opinião popular", ressalta que a Corte não precisa e não deve ter como foco agradar a sociedade, pelo contrário, por vezes, deverá atuar em desconformidade com a aparente vontade da maior parte da população para assegurar a integridade do pacto constitucional, de forma que acarretaria uma terrível contradição decidir pela constitucionalidade da referida legislação com base na opinião majoritária para posteriormente exercer a função contramajoritária ao suspender a elegibilidade de agentes políticos que submetem-se ao controle majoritário por excelência, o processo eleitoral. 
Deste modo, o objetivo da accountability social se insere na necessidade de democratização do Poder Judiciário para torná-lo mais dialógico e promover a participação social equitativa especialmente em suas estruturas internas de Política Judiciária. Com isso, fortalecendo a função contramajoritária e rompendo com as barreiras que isolam o Judiciário da sociedade.

Em regra, os mecanismos de controle e responsabilização privilegiam as formas tradicionais institucionais e acabam por menosprezar a atuação da sociedade civil, ignorando as formas alternativas de controle que dependem essencialmente das organizações sociais atreladas aos veículos de comunicação (PERUZOTTI e SMULOVITZ, 2006, p. 04). Com isso, fortalece o modelo autônomo-corporativo que se demonstra ineficaz para uma gestão adequada no regime democrático por favorecer o corporativismo e o próprio isolamento da magistratura.

Assim como ocorre no cenário brasileiro, em que os mecanismos de accountability se inserem na modalidade horizontal ou intra-estatal, na qual a fiscalização é realizada pelos próprios agentes ou órgãos estatais que nos limites de suas competências podem requerer justificações sobre os atos executados e aplicar sanções quando necessário. Neste modelo se faz indispensável a existência de agências ou órgãos de supervisão voltados a fiscalizar, controlar, retificar ou sancionar as ações ilícitas cometidas por outros agentes estatais, de forma autônoma com autoridade legal e também de fato em relação aos outros poderes e pressões externas. (O’DONNELL, 1997, p. 42)

A terminologia accountability em sentido amplo, busca abarcar a necessidade de o agente público prestar informações sobre os atos praticados, justificá-las de forma adequada, e a possibilidade de sofrer sanções quando houver alguma violação legal, sanções que poderão ser na esfera política, jurídica ou social. (SCHEDLER, 1999)

Deste modo, engloba dois sujeitos, o mandante, detentor do controle, o qual não poderá exercer de forma plena a engessar as ações, e o agente, que fornece as informações e sempre estará suscetível a sanções por parte dos mandantes, as quais estimulam para um comportamento mais benéfico em prol da sociedade, vedando condutas indevidas. (TOMIO e ROBL FILHO, 2013, p. 31)

Já no que concerne à modalidade vertical, consiste naquela que é exercida sob os agentes ou órgãos estatais pela sociedade em geral, contendo duas grandes ramificações (I) eleitoral, por meio do sufrágio o cidadão poderá sancionar os agentes conforme seus atos pretéritos; e a (II) social, objeto principal deste estudo, a qual ocorre por meio da cidadania ativa com organizações da sociedade civil organizada por meio de denúncias e exposição pública dos atos com auxilio dos mecanismos de imprensa. (PINHO e SACRAMENTO, 2009, p. 1351)

A modalidade social decorre diretamente da atuação da sociedade civil ativa com os mecanismos de mídia, de modo que busca compensar os deficits institucionais considerando que 
expõem as irregularidades e impulsiona a atuação dos órgãos estatais responsáveis. Além de que diferente da modalidade eleitoral, sua eficácia não depende do número de cidadãos engajados, mas da visibilidade e intensidade de atuação de determinados grupos específicos com determinados objetivos. (BARBOSA e RODRIGUES, 2020)

Assim, pode-se afirmar que os mecanismos de accountability social complementam e aprimoram os mecanismos convencionais de accountability, corroborando de forma mútua, possibilitando que algumas iniciativas sociais, ou aberturas do próprio Estado, institucionalizem a participação social por meio de procedimentos transparentes e mais abertos ao envolvimento da sociedade, dando ensejo à um mecanismo híbrido ou transversal. (MALENA e FORSTER, 2004, p. 3-4)

No contexto latino americano, especificamente no Brasil, verifica-se a ausência de força suficiente das organizações sociais para promover essa institucionalização da participação social nos processos de tomada de decisão estatal, pois a democracia não se vislumbra materialmente consolidada. Encontrando fortes traços daquilo que O’Donnell classifica como democracia delegativa, comum na transição de regimes autoritários, nas quais a participação cidadã se resume ao pleito eleitoral para posteriormente tornar-se mero expectador do governo eleito. (ABBOUD, 2018, p. 830-832)

A condição de democracia delegativa não pressupõe necessariamente a iminência de governos autoritários, todavia, verifica-se que não há um progresso acerca dos avanços para aprimorar a representação e participação política, utilizando-se das eleições como forma de sustentar certa legitimidade e aparência democrática, bem como o fundamento para que o presidente busque governar da forma com que considerar adequado. (O’DONNELL, 1991, p. 26-31)

Os dizeres de O’Donnell (1991, p.36) encontram eco perfeito na atual realidade político social brasileira, "os presidentes se elegem prometendo que - fortes, corajosos, acima dos partidos e interesses, machos - salvarão o país. O governo deles é um 'governo de salvadores." O iminente fracasso de governo fragiliza as instituições estatais perante a sociedade, levando a pressupor que todos os governos agirão de forma semelhante. (O’DONNELL, 1991, p. 36)

Neste sentido, cabe ressaltar que a cidadania não se resume à manifestação no pleito eleitoral, mas sim uma ampla e frequente sistemática de participação, desde orçamentos participativos à atuação de organizações da sociedade civil nos processos de tomada de decisão e realização de denúncias, exposição pública. (SILVA, 1995, p. 186)

Sem dúvidas, a democracia consiste um pré-requisito indispensável, mas não gera por si uma cultura de civilidade e participação ativa dos cidadãos, havendo necessidade de que as 
instituições estatais, neste caso o Judiciário, promovam aberturas para participação popular e engajamento com questões publicas, a fim de alcançar deliberações democráticas que podem se adequar aos anseios sociais. (OFFE, 1999, p. 143-144)

Nesta toada, se faz necessário lembrar que a socialidade, princípio social, figura como elemento estruturante do Estado Constitucional, de modo que deverão haver mecanismos de intervenção social nas estruturas estatais, influencia das organizações sociais nas decisões políticas centrais com objetivo primordial de consolidar e aprofundar a democracia para que o cidadão seja deslocado da postura de "recipiente" para "participante" daquele conjunto social. (NETTO, 2009, p. 124-126)

Além das indispensáveis aberturas institucionais do Judiciário para promover a participação social na esfera da Administração da Justiça, principalmente órgãos de controle, planejamento e responsabilização, denota-se a iminente demanda social para integrar a esfera deliberativa de controle concentrado de constitucionalidade, haja vista o cenário de juristocracia em que as controversas transcendem a esfera jurídica para a política, tornando imperiosa a participação social para que tenham maior legitimidade.

Neste sentido, Häberle adverte que o povo constitui-se como elemento ativo e pluralista que deverá influir neste processo para maximizar sua legitimidade por tratar-se de um direito inerente à cidadania, pois neste processo dever-se-á considerar todas as pluralidades que compõe a sociedade garantindo igualdade de participação entre os diversos grupos, transcendendo a ideia de que o povo se manifesta apenas nas eleições e buscando aproximar a Corte da sociedade. (HÄBERLE, 1997, p. $14 ; 36 ; 37)$

Portanto, a partir desta perspectiva, defende-se que devem ser instituídos mecanismos de accountability social na esfera da Política Judiciária e organização de seus respectivos órgãos, bem como na esfera de controle concentrado de constitucionalidade em função da intima relação com questões políticas para que as decisões sejam fruto de um processo de deliberação democrático envolvendo debates de amplos setores da sociedade, sem, todavia, considerar que meras maiorias estarão moldando a decisão, pois todas as parcelas sociais deverão participar de forma igualitária.

\section{CONSIDERAÇÕES FINAIS}

O protagonismo exercido pelo Poder Judiciário no cenário brasileiro é suficiente para caracterizar o fenômeno da juristocracia a partir da preservação hegemônica do poder por parte das 
elites que buscaram a manutenção de seus interesses, bem como influir em pleitos eleitorais democráticos para que que determinados atores políticos não lograssem êxito nas eleições.

Este papel exercido pelo Poder Judiciário encontra respaldo no Código de Processo Civil que incumbe às Cortes Superiores um papel semelhante ao legislador ordinário a partir da fixação de entendimentos jurisprudenciais vinculantes, dificultando a revisão destes entendimentos por ausência de procedimentos adequados, bem como transferindo ao Judiciário tarefa qual não lhe foi atribuída constitucionalmente.

A juristocracia resta-se fortalecida pela ausência de mecanismos de controle e responsabilização externos do Poder Judiciário e seus respectivos membros uma vez que o modelo de responsabilidade se caracteriza como autônomo-corporativo, ou seja, contempla apenas mecanismos internos que em regra pautam-se no corporativismo e não obtém eficiência em estimular comportamentos benéficos para sociedade.

Portanto, o fenômeno em questão figura como uma forma das elites preservarem seus interesses diante da ascensão de atores políticos contrários à estes, e, por vezes, impedindo sua ascensão democrática a partir de atuações estratégicas do Judiciário, além de servir para transferir a responsabilidade sobre questões controversas que demandam custos políticos para uma esfera teoricamente técnica.

Neste ínterim, insere-se a indispensável demanda por accountability social para possibilitar a transformação do modelo autônomo-corporativo para um modelo que considere a sociedade como consumidora do sistema de justiça, e, portanto, com sensíveis brechas para atender suas demandas e corresponder às suas legitimas expectativas, maximizando sua legitimidade.

Assim, defende-se a necessidade de instituir mecanismos eficazes de accountability social em duas esferas principais sendo (I) Política Judiciária e Administração da Justiça possibilitando a participação social na esfera de gestão e organização dos órgãos que compõem o sistema de justiça, gestão de recursos, definição de metas e responsabilização disciplinar dos membros, e (II) Controle Concentrado de Constitucionalidade para viabilizar a construção de uma decisão democrática a partir da participação dos cidadãos no processo interpretativo, para os casos que contemplem controversas que transcendam a esfera jurídica os quais deveriam estar sendo debatidos no campo político, mas foram transferidos em virtude do protagonismo judicial.

Desta forma, constata-se que os mecanismos de accountability social diretamente interligados com a cidadania ativa e participação social nas esferas decisórias não são contrários à função contramajoritária do Poder Judiciário, uma vez que fortalecem-na a partir da participação 
igualitária de diversas organizações sociais seja na esfera de gestão ou deliberação judiciária, possibilitando que o Judiciário exerça a função contramajoritária com maior legitimidade.

Com isso, a adoção dos referidos mecanismos a partir de aberturas institucionais para possibilitar a participação cidadã efetiva o princípio da socialidade e para densificar o próprio modelo democrático, de modo que resultará diretamente no enfraquecimento do fenômeno da juristocracia e maximização da legitimidade do Poder Judiciário perante a sociedade.

\section{REFERÊNCIAS}

ABBOUD, Georges. Processo constitucional brasileiro. 2. ed., rev., atual. e ampl. São Paulo: Revista dos Tribunais, 2018.

ABBOUD, Georges. Submissão e Juristocracia. Revista de Processo, vol. 258, 2016.

ARGUELHES, Diogo Werneck; RIBEIRO, Leandro Molhano. Ministrocracia: O Supremo Tribunal individual e o processo democrático brasileiro. Novos estudos CEBRAP, v. 37, n. 1, p.13$32,2018$.

BARBOSA, Claudia Maria. A Juristocracia no Brasil e o Futuro da Constituição. Revista Eletrônica do Curso de Direito da UFSM. v. 14, n. 2, 2019.

BARBOSA, Claudia Maria; RODRIGUES, Lucas Troyan. A Accountability Social no Judiciário Brasileiro. Revista de Política Judiciária, Gestão e Administração da Justiça, v. 6, p. 19-39, 2020.

CAPPELLETTI, Mauro. Juízes irresponsáveis. P. Alegre : S.A. Fabris, 1989.

GARAPON, Antonie. O juiz e a democracia: o guardião de promessas. Tradução: Maria Luiza de Carvalho. Rio de Janeiro : Revan, 1999.

HÄBERLE, Peter. Hermenêutica constitucional: a sociedade aberta dos intérpretes da constituição: contribuição para a interpretação pluralista e 'procedimental' da constituição. Porto Alegre: S. A. Fabris, 1997.

HIRSCHL, Ran. The new constitutionalism and the judicialization of the pure politics worldwide. Fordham Law Review, v. 75, n. 2, 2016.

MALENA, Carmem, FORSTER, Reiner; SINGH, Janmejay. Social Accountability: an introduction to the concept and emerging practice. The World Bank. Washinton DC, 2004, Paper n. 76, 24 p. (Participation and Civic Engagement Serie).

NERY JUNIOR, Nelson; ABBOUD, Georges. O CPC/2015 e o risco de uma juristocracia: a correta compreensão da função dos tribunais superiores entre o ativismo abstrato das teses e o julgamento do caso concreto. Revista Brasileira de Direito Processual, n. 93, Jan./Mar., 2016.

NETTO, Luísa Cristina Pinto e. Os direitos sociais como limites materiais à revisão constitucional. Salvador: Editora Juspodivm, 2009. 
O’DONNELL, Guillermo. Accountability Horizontal e Novas Poliarquias. Lua Nova, São Paulo, n. $44, \quad$ p.27-54, 1997. Disponível em: <http://www.scielo.br/scielo.php?pid=S0102$64451998000200003 \&$ script=sci_abstract\&tlng=pt $>$. Acesso em: 31 de outubro de 2017.

O’DONNELL, Guillermo. Democracia Delegativa?. Novos Estudos CEBRAP. No 31, p. 24-40, out. 1991. Disponível em: 〈http://uenf.br/cch/lesce/files/2013/08/Texto-2.pdf〉. Acesso em 05 jun. 2020.

OFFE, Claus. A Atual transição da história e algumas opções básicas para as instituições da sociedade. In: PEREIRA, Luiz Carlos Bresser; WILHEIM, Jorge. SOLA, Lourdes (Orgs.). Sociedade e Estado em transformação. São Paulo: UNESP; Brasília: ENAP, 1999.

PERUZOTTI, Enrique e SMULOVITZ, Catalina. Social Accountability: as introduction. In: PERUZOTTI, E. e SMULOVITZ, C. Enforcing the rule of law: social accountability in the new latin american democracies. University of Pittsburgh Press., 2006, p. 03-33.

PINHO, José Antonio Gomes de; SACRAMENTO, Ana Rita Silva. Accountability: já podemos traduzi-la para o português?. Revista de Administração Pública, vol. 43, n. 6, p.1343-1368, Nov./Dez., 2009.

REZENDE, Maurício Corrêa de Moura. Democratização do poder judiciário no Brasil. São Paulo: Contracorrente, 2018.

SILVA, Ricardo. Democracia Delegativa ou Vícios de Transição?. Revista de Sociologia e Política. nº4/5, 1995. Disponível em: <https://revistas.ufpr.br/rsp/article/view/39367/24184>. Acesso em 29 mai. 2020.

TOMIO, Fabrício Ricardo de Limas; ROBL FILHO, Ilton Norberto. Accountability e Independência Judiciais: Uma análise da Competência do Conselho Nacional de Justiça (CNJ). Revista de Sociologia e Política, vol. 21, n. 45, p.29-46, mar. 2013.

VIEIRA, Oscar Vilhena. Supremocracia. Revista Direito GV, p.441-464, Jul./Dez., 2008. Disponível em: <http://www.scielo.br/pdf/rdgv/v4n2/a05v4n2.pdf>. Acesso em: 28 de outubro de 2019. 